\title{
Penggunaan Load Balancing Pada Web Server Lokal Dengan Metode Policy Based Routing
}

\author{
Setiyo Eko Budiyono ${ }^{1}$, Tatang Rohana ${ }^{2}$, Tohirin Al Mudzakir ${ }^{3}$ \\ 1,2,3 Teknik Informatika, Fakultas Teknik Dan Ilmu Komputer, Universitas Buana Perjuangan Karawang. \\ setiyoekob@gmail.com ${ }^{1}$, tatang.rohana@ubpkarawang.ac.id ${ }^{2}$, tohirin@ubpkarawang.ac.id ${ }^{3}$
}

\begin{tabular}{l}
\hline Article Info \\
\hline Article history: \\
Received Jun $12^{\text {th }}, 2021$ \\
Revised Aug $20^{\text {th }}, 2021$ \\
Accepted Aug $31^{\text {th }}, 2021$
\end{tabular}

\section{Keyword :}

load balancing;

jaringan komputer;

policy based routing,

\begin{abstract}
Perkembangan teknologi jaringan komputer menjadi kebutuhan mutlak sebagai sarana penunjang kegiatan pada instansi-instansi saat ini. Teknologi jaringan komputer tersebut dimanfaatkan oleh SMK Jayabeka 01 Karawang sebagai sarana mengevaluasi kemampuan peserta didiknya dengan melakukan ujian berbasis komputer. Ujian dilakukan dengan menggunakan jaringan lokal dan aplikasi berbasis web server. Jaringan komputer yang digunakan sebagai sarana ujian berbasis komputer masih memiliki kekurangan, yaitu masih manualnya pembagian client yang harus mengakses server ujian dimana aplikasi ujian berbasis http. Ketika terjadi kegagalan pada web server, maka client harus dipindah secara manual ke server yang lain. Dengan permasalahan yang ada diperlukan jaringan yang dapat menyelesaikan permasalahan itu, maka dibuatlah jaringan dengan konfigurasi load balancing yang diterapkan supaya client dapat mengakses web server yang lain secara otomatis apabila ada link server yang bermasalah/putus koneksi. Metode yang digunakan untuk load balancing adalah Policy Based Routing, metode dengan mengelompokkan hak akses berdasarkan Src-address maupun Dst-address. Metode policy based routing melakukan prosesnya berdasarkan per-packet load balancing, perconnection load balancing dan per-address-pair load balancing. Dengan penggunakan metode load balancing, client akan tetap mendapatkan layanan meskipun ada link server yang mengalami gangguan koneksi, sehingga fungsi keseluruhan jaringan tidak akan terganggu.
\end{abstract}

Copyright (C) 2021 STMIK Triguna Dharma. All rights reserved.

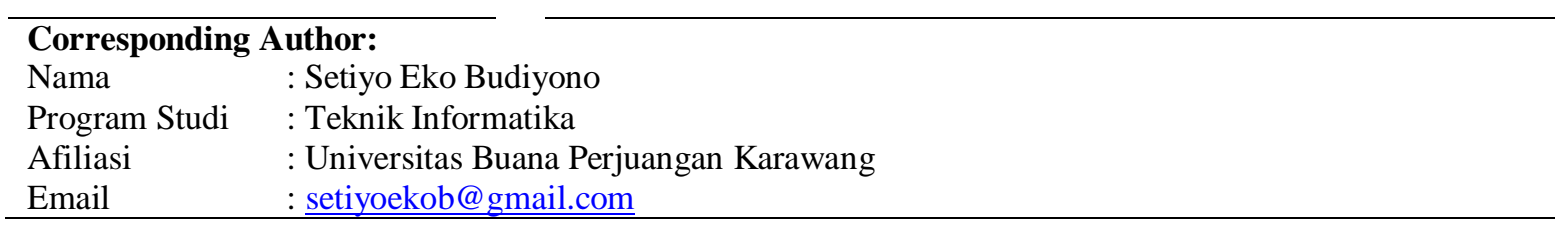

\section{PENDAHULUAN}

Load balancing pada web server merupakan teknik yang digunakan untuk membagi beban kerja pada beberapa web server secara merata, sehingga beban kerja server karena permintaan layanan dari client akan lebih ringan dan kinerja server akan lebih optimal. Protokol load balancing merupakan protokol yang digunakan untuk mendistribusikan beban traffic pada jaringan komputer yang memiliki dua atau lebih jalur koneksi secara seimbang. Pendistribusian ini dimaksudkan supaya beban yang ada pada traffic jaringan lebih seimbang, menghindari overload yang terjadi pada salah satu jalur koneksi, dan memaksimalkan throughput sehingga waktu tanggap layanan dalam jaringan akan lebih kecil. Teknik load balancing sendiri merupakan bagian dari mekanisme kerja protokol routing dalam jaringan. Mekanisme routing ini bekerja dengan cara membagi beban traffic pada jaringan secara merata atau seimbang.

Permasalahan overload pada server dialami juga oleh server ujian di Sekolah SMK Jayabeka 01 Karawang, dimana ketika pelaksanaan ujian link server mengalami down yang mengakibatkan user harus dipindahkan ke server yang lain secara manual. Untuk menghindari terjadinya link server yang down, maka sekolah SMK Jayabeka 01 Karawang melakukan pembagian user dengan menyediakan banyak server. Hal ini akan merepotkan administrator jaringan untuk mengontrol kinerja server dalam jaringan ketika pelaksanaan ujian sedang berlangsung. Salah satu cara yang dapat dilakukan untuk meminimalisasi kejadian itu dengan 
memanfaatkan teknik load balancing dan failover, dimana dengan teknik ini pembagian beban kerja link server akan lebih seimbang, dan tentu saja akan mengoptimalkan kinerja server tersebut.

Metode dalam load balancing ada berbagai macam, diantaranya metode Equal Cost Multi Path (ECMP) menggunakan teknik equal cost, metode Nth dengan teknik round robin, Metode Per Connection Clasifier (PCC) menggunakan teknik hashing dan compairing, dan metode Policy Based Routing (PBR) dengan teknik memetakan traffic (Route Map) berdasar src-address atau dst-address.. Metode-metode load balancing tersebut memiliki karakteristik sendiri-sendiri dan mempunyai kelebihan serta kekurangan[1].

\section{METODOLOGI PENELITIAN}

Metode yang digunakan dalam pembuatan jaringan komputer yaitu analisis kebutuhan sistem, perancangan, implementasi, monitoring dan management. Tahap pertama dalam pembuatan jaringan yaitu analisis kebutuhan yang diperlukan untuk membangun jaringan komputer berupa perangkat lunak dan perangkat keras. Perangkat lunak (software) yang diperlukan yaitu Microsoft Windows 10 digunakan untuk Operating System (OS) komputer Server, XAMPP dengan Apache yang berfungsi untuk web server lokal, winbox sebagai aplikasi untuk konfigurasi router, tools mikrotik Torch untuk mengukur traffic, Graphing untuk monitoring beban kerja jaringan dan browser (chrome, firefox) untuk menampilkan hasil request client[9].

Perangkat keras yang diperlukan diantaranya laptop Asus A456U Series, dengan spesifikasi Processor Intel(R) Core(TM) i5-7200U, dengan Ram 4GB, Router Mikrotik dengan spesifikas, RB750 (hEX-Lite) 5 buah port ethernet 10/100Mbps, dengan prosesor Qualcom QCA9531-BL3A- R 850MHz, lisensi level4.

Tahap kedua yaitu desain, merupakan tahapan perancangan topologi jaringan yang dapat bekerja dengan baik dan sesuai dengan kebutuhan. Tahap ketiga merupakan tahap pembuatan prototype dan implementasi pada jaringan yang sebenarnya. Pada tahap ini konfigurasi dilakukan, install xampp untuk web server, dan konfigurasi router mikrotik menggunakan winbox. Tahap konfigurasi pada router meliputi konfigurasi dasar, konfigurasi Policy Based Routing dan komfigurasi Failover.

Tahapan selajutnya adalah pengujian dari perancangan dan konfigurasi pada jaringan. Pada tahap ini dilakukan pengujian terhadap kinerja failover dan load balancing dengan metode policy based routing. Dengan pengujian ini diharapkan dapat mengetahui apakah hasil perancangan sesuai dengan perencanaan awal.

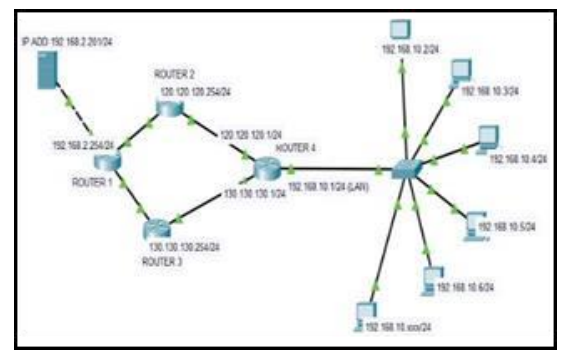

Gambar 1. Topologi Jaringan LAN

\section{ANALISA DAN HASIL}

Pada tanap hasil dan pembahasan ini akan dibahas tentang hasil dari penggunaan load balancing dengan metode policy based routing dan failover yang terapkan pada jaringan komputer.

\subsection{Install Xampp}

Xampp dengan Apache sebagai web server diinstall pada komputer server yang nantinya akan diakses oleh komputer client. Untuk melakukan instalasi xampp terlebih dahulu download aplikasi xampp dari https://www.apachefriends.org/download.html, setelah itu jalankan proses instalasi sampai selesai. Tampilan xampp setelah selesai instalasi : 


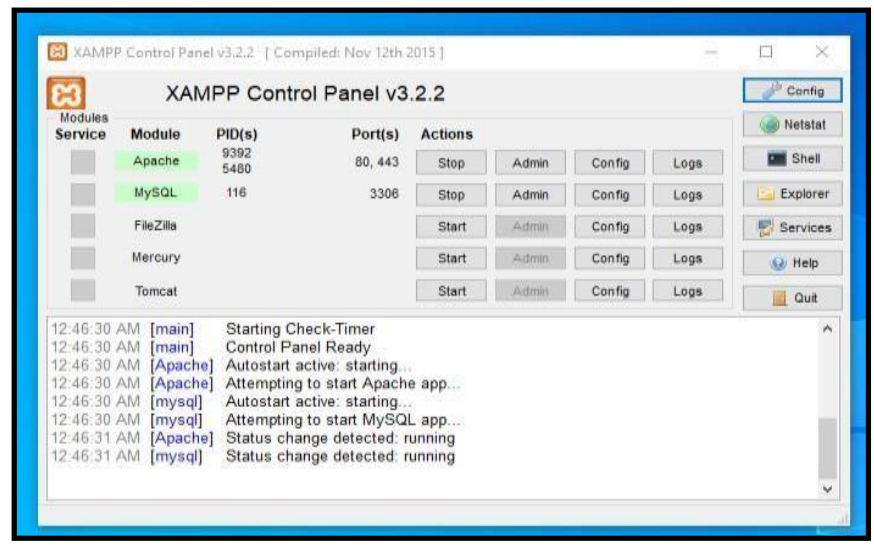

Gambar 2. Tampilan xampp aktif

\subsection{Konfigurasi Policy Based routing (PBR)}

Konfigurasi policy based routing (PBR) dilakukan denganmenggunakan aplikasi winbox., ada beberapa konfigurasi yang dilakukan saat konfigurasi dasar pada mikrotik diantaranya identity router, IP addres, domain name system (DNS), dan Network Address Translation (NAT). Konfigurasi identity router ini dilakukan untuk pemberian identitas router dan port Ethernetnya, dengan script berikut ini :

[admin@MikroTik] > system identity set name=Router4 (Memberi identitas Router) / [admin@Router4] > interface set ether1 name=ether1-JALUR1 (memberi identitas port ethernet 1) /[admin@Router4] > interface set ether2 name=ether2- JALUR2 (memberi identitas port ethernet 2 )/ [admin@Router4] > interface set ether4 name=ether4- LAN (memberi identitas Ethernet4 yang kearah jaringan lokal / client).

Konfigurasi IP address dilakukan dengan script berikut : [admin@Router4] > ip address add address=120.120.120.1/24 interface=ether1-JALUR1 [admin@ Router4]

\section{JALUR2}

$>\quad$ ip address add address $=130.130 .130 .1 / 24$ interface=ether2-

[admin@Router4] $\quad>\quad$ ip $\quad$ address $\quad$ add address=192.168.10.1/24 interface=ether4-

Konfigurasi DNS menggunakan script: [admin@Router4] > ip dns set servers $=1.1 .1 .1,192.168 .2 .1$

Konfigurasi NAT menggunakan script berikut : [admin@ Router4] > ip firewall nat add chain=srcnat action=masquarade out-interface=ether1-JALUR1 connection-mark=via-JALUR1

[admin@Router4] > ip firewall nat add chain=srcnat action=masquarade out-interface=ether2JALUR2 connection-mark=via-JALUR2

Konfigurasi policy based routing terdiri dari konfigurasi ip address list, konfigurasi mangle, konfigurasi gateway dan failover. Konfigurasi ip address list menggunakan script : [admin@ Router4] > ip firewall address-list add

lis=GROUP1 address=192.168.10.2 [admin@ @outer4] > ip firewall address-list add lis=GROUP2 address $=192.168 .10 .51$

Konfigurasi Mangle dengan script :

[admin@Router4] > ip firewall mangle add chain=prerouting $\quad$ src-address-list=GROUP1 action=mark-routing new-routing-mark=via-JALUR1 passthrough=yes

[admin@Router4] > ip firewall mangle add chain=prerouting src-address-list=GROUP2 action=mark-routing new-routing-mark=via-JALUR2 passthrough=yes

Konfigurasi gateway dan failover menggunakan script : [admin@ Router4] route add gateway $=192.168 .10 .1$

ip

routing-mark=via-JALUR1 distance $=1$

[admin@ Router4] > ip route add dst-address=0.0.0.0/0 gateway=130.130.130.2 routing-mark=viaJALUR2 check-gateway=ping 


\subsection{Pengujian}

Pengujian jaringan dilakukan dengan melakukan ping dan tracert dari komputer client dalam daftar GROUP1 pada address-list. Pada saat dilakukan test ping dan traceroute (tracert) dapat dilihat bahwa jalur yang digunakan sesuai dengan pengaturan jalur pada firewall - Mangle yaitu melalui JALURI. hal itu diketahui dari ip address yang dilalui paket data dari komputer client (192.169.10.11) menuju komputer server (ip address 192.168.2.201) yang merupakan tujuan dari paket data, yaitu melalui ip 192.168.10.1 120.120.120.254 - 10.10.10.2 - SMKJAYABEKA01 (192.1682.201), dimana ip 120.120.120.254 10.10.10.2 merupakan ip JALUR1. Hasil berbeda di tunjukkan pada proses traceroute dari komputer client dengan ip address 192.168.10.61, dimana ip komputer ini masuk dalam GROUP2 pada address-list. Pada saat melakukan perintah tracert, jalur/rute yang dilalui adalah ip address 192.168.10.1 - 130.130.130.254 20.20.20.2 - SMKJAYABEKA01 (192.1682.201) yang merupakan ip JALUR2.

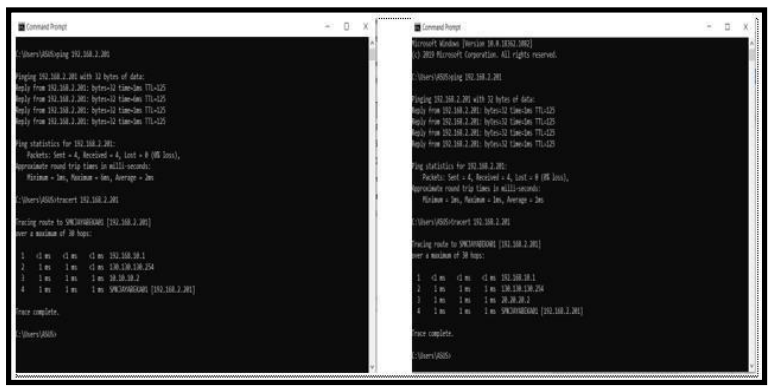

Gambar 3. Menguji jaringan dengan ping dan tracert

A. Pengujian Failover

Pengujian failover dilakukan untuk mendapatkan hasil kinerja jaringan komputer ketika ada link akses yang mengalami masalah atau mati.

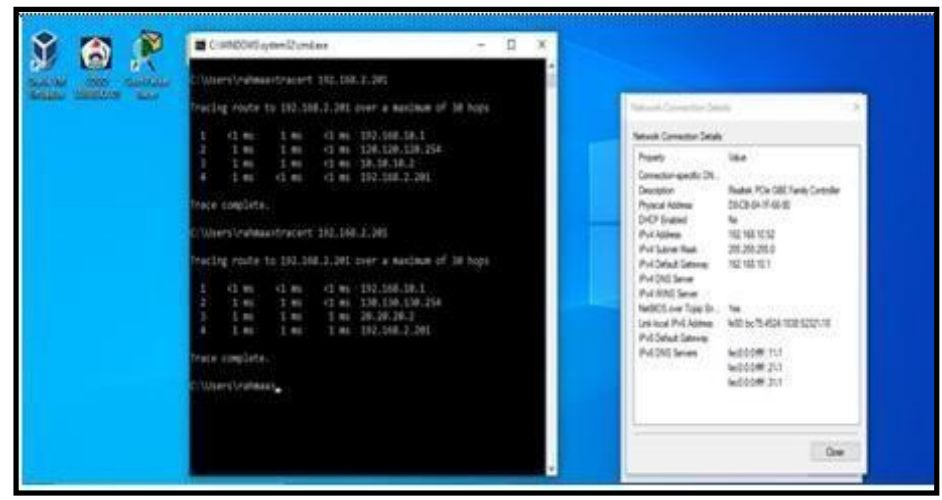

Gambar 4. Pengujian failover

Ketika dilakukan perintah traceroute (tracert) dari komputer client dengan ip address 192.168.10.52 (GROUP2) tujuan ip server (192.168.2.201), jalur/rute yang dilewati yaitu 192.168.10.1 - 120.120.120.254 10.10.10.2 - 192.168.2.201 dimana jalur/rute ini merupakan jalur pada interface etherl-JALUR1 yang merupakan jalur default untuk address-list GROUP1. Pada saat link interface2- JALUR2 diaktifkan kembali, maka komputer dengan ip 192.168.10.52 tadi ketika dilakukan perintah tracert menuju ip server akan melewati jalur defaulnya yaitu 192.168.10.1 - 130.130.130.254 - 20.20.20.2 - 192.168.2.201 yang merupakan jalur default address-list GROUP2. Pengujian dapat dilihat pada gambar 4. 


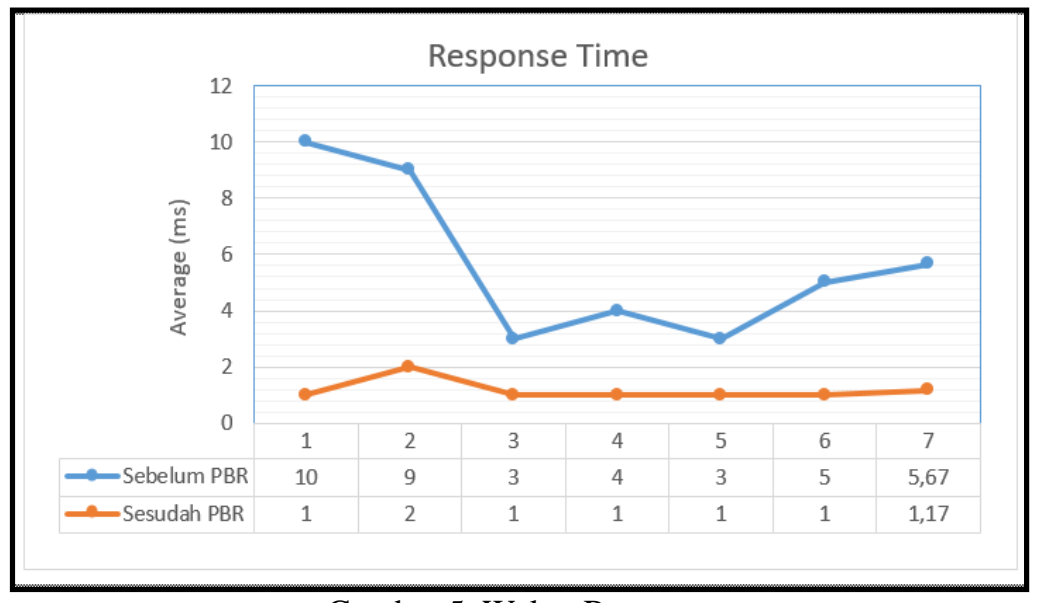

Gambar 5. Waktu Response

Pengujian response time dilakukan sebelum dan sesudah penggunaan policy based routing

Tabel 1. Hasil pengujian respon time

\begin{tabular}{|c|c|c|c|c|}
\hline \multirow[b]{2}{*}{ Text } & \multirow[b]{2}{*}{ Paket } & \multicolumn{3}{|c|}{$\begin{array}{c}\text { Respon Time } \\
(\mathrm{ms})\end{array}$} \\
\hline & & $\begin{array}{c}\text { Sebelum } \\
\text { Penggunaan } \\
\text { Policy Based } \\
\text { Routing }\end{array}$ & $\begin{array}{c}\text { Menggunakan } \\
\text { Policy Based } \\
\text { Routing }\end{array}$ & Selisih \\
\hline I & 32 bytes & 10 & 1 & 9 \\
\hline II & 32 bytes & 9 & 2 & 7 \\
\hline III & 32 bytes & 3 & 1 & 2 \\
\hline IV & 32 bytes & 4 & 1 & 3 \\
\hline V & 32 bytes & 3 & 1 & 2 \\
\hline VI & 32 bytes & 5 & 1 & 4 \\
\hline & a-rata & 5,67 & 1,17 & 4,50 \\
\hline
\end{tabular}

Untuk melayani pengiriman data, terjadi peningkatan kecepatan waktu yang diperlukan, dengan besar paket data 32 bytes terdapat peningkatan $4,50 \mathrm{~ms}$ dari sebelumnya memerlukan waktu $5,67 \mathrm{~ms}$ menjadi $1,17 \mathrm{~ms}$, berarti setelah menggunakan policy based routing ada peningkatan kecepatan waktu yang dibutuhkan server untuk melayani permintaan dari client.

\section{KESIMPULAN}

Dari hasil penelitian yang dilakukan dapat disimpulkan sebagai berikut :

1. Load balancing dengan metode policy based routing bekerja berdasar parameter src-address mauapun dst- address, yaitu mengatur akses keluar masuk data yang melalui router, aturan ini disebut dengan route-map

2. Penggunaan load balancing dengan metode policy based routing dapat mengatur dan menyeimbangkan akses web server lokal, Dengan adanya load balancing ini, dapat meminimalisasi penggunaan server untuk melayani request dari client.

3. Untuk link akses dari pengaturan ini mengenali setiap ip address yang melalui router load balancing, dimana ip address yang berasal dari GROUP1 ketika mengakses server akan dilewatkan melalui JALUR1, ketika ip address dari komputer yang mengakses server berasal dari GROUP2, maka jalur akan dilewatkan melalui JALUR2. sehingga tidak terjadi penumpukan beban jalur pada waktu yang bersamaan. Dan pada saat salah satu jalur mengalami gangguan, maka akses dari client akan dialihkan melalui jalur yang lain, disinilah fungsi dari failover itu berlangsung

\section{REFERENSI}

[1] Kadir, A. \& Triwahyuni, T. C. (2013), Pengantar Teknologi Informasi Edisi Revisi, Andi Offset, Yogyakarta 
[2] Novianto, A.,.( 2017) Pemrograman Web. Jakarta: Penerbit Erlangga

[3] Nurfajar, A., Kurniawan, M. T. \& Yunan K.S.H, U "Desain dan Analisa Infrastruktur Jaringan Wired Di PDIILIPI Jakarta Dengan Menggunakan Metode Network Development Life Cycle (NDLC). e- Proceeding of Engineering (ISSN : 2355-9365), Vol.2, No.2, p. 5359, 2015

[4] Patwiyanto, Wahyuni, S. \& Prasetyo, S. A., " Admisitrasi Sistem Jaringan". Penerbit Andi, Yogyakarta, Indonesia, 2017

[5] Rachmawan, D., Irwan, D. \& Argyawati, H., "Penerapan Teknik Load Balancing Pada Web Server Lokal dengan Metode NTH Menggunakan Mikrotik”. Jurnal Penelitian Ilmu Komputer, System Embedded \& Logic, 4(2), pp. 98-108, 2016

[6] Sukaridhoto, S., “Jaringan Komputer I”. Surabaya: Politeknik Elektronika Negeri Surabaya (PENS), 2014

[7] Sutrisno, “Administrasi Infrastruktur Jaringan” PT. Bumi Aksara Dan CV. Armico. Jakarta, 2019

[8] Syaputra, A. W. \& Assegaff, S., "Analisis Dan Implementasi Load Balancing Dengan Metode Nth Pada Jaringan Dinas Pendidikan Provinsi Jambi”. Jurnal Manajemen Sistem Informasi (ISSN: 2528- 0082), Vol. 2, No.4, p. 14, 2017

[9] Towidjojo, R., “Mikrotik Kungfu Kitab 4”. Jasakom, Palu, Indonesia, 2016 